\title{
Robot-assisted pyeloplasty: Outcomes for primary and secondary repairs, a single institution experience
}

Matthew R. Thom, Mohammed Haseebuddin, Timur M. Roytman, Brian M. Benway, Sam B. Bhayani, Robert S. Figenshau

Division of Urologic Surgery, Washington University in St Louis, USA

\section{ABSTRACT}

Introduction: Robotic Pyeloplasty (RAP) is a technique for management of ureteropelvic junction obstruction (UPJO).

Purpose: To report outcomes of RAP for primary and secondary (after failed primary treatment) UPJO.

Materials and Methods: Single institution data of adult RAP performed from 2007 to 2009 was collected retrospectively following approval by our IRB. Database analysis included patient age, race, pre and post-operative imaging studies and perioperative variables including operative time, blood loss, pain and complications.

Results: Fifty-five adult patients underwent RAP (26 left/29 right) for UPJO including 9 secondary procedures from 2007 to 2009. Average follow-up was 16 months (1-36). Mean age was 41 years (18-71) with an average BMI of 27 (17-42); 32 were female. Most patients were diagnosed with preoperative diuretic renal scintigraphy and the obstructed side demonstrated mean function of $41 \%$ and $t 1 / 2$ of 70 minutes. Mean operative time was 194 minutes with average blood loss less than 100 mL. Mean hospital stay was 1.7 days with an average narcotic equivalent dose of $15 \mathrm{mg}$. RAP for secondary UPJO took longer with more blood loss and had a lower success rate. Failure was defined as the need of another procedure due to persistent pain and/or obstruction after diuretic renal imaging. One patient (2\%) with primary UPJO failed and 2 patients (22\%) with secondary UPJO failed. One major complication occurred.

Conclusion: RAP is a good option for the treatment of patients with UPJO. Reported series have established that endopyelotomy has inferior success rate for the treatment of primary UPJO which compromises the success of subsequent treatment as demonstrated in our higher failure rate with secondary UPJO repair.

\section{ARTICLE INFO}

\section{Key words:}

Kidney; robotics; outcomes; uretero-pelvic junction obstruction

Int Braz J Urol. 2012; 38: 77-83

Submitted for publication:

February 02, 2011

Accepted after revision:

June 30, 2011

\section{INTRODUCTION}

Ureteropelvic junction obstruction (UPJO) is a disease of the proximal ureter resulting from both congenital and acquired causes. Open pyeloplasty remains the comparative gold standard for treatment (1-3). As an attempt to decrease associated morbidity of an open procedure, less invasive endoscopic techniques such as endopyelotomy were developed, but long-term outcomes were not as good as expected (4-6). Success of laparoscopic pyeloplasty is equivalent $(7,8)$; however, due to its technical complexity, many urologists still perform a significant number of open and endoscopic 
procedures (9). This trend is rapidly changing as more surgeons become familiar with laparoscopic techniques and the rapid advancement of the robotic platform has eased the transition of the open surgeon into the era of minimally invasive surgery. We report our institutional outcomes of roboticassisted pyeloplasty (RAP) for primary and secondary UPJO with the goal of contributing further evidence supporting RAP for primary UPJO repair.

\section{MATERIALS AND METHODS}

Medical records were retrospectively reviewed on all patients treated with RAP for UPJO at our institution from 2007 to 2009. Patient age, race, UPJO characteristics including pre-operative imaging, operative statistics (time, blood loss, complication), and post-operative follow-up information were recorded. Differentiation between primary and secondary repairs was made and included in final analysis. All patients were identified as having UPJO based on presenting symptoms and renal imaging, most often with nuclear diuretic renal scan (40 patients, 72\%). UPJO was defined as clinically significant when obstructive hydronephrosis with diuretic renal scan was demonstrated $t 1 / 2>20$ minutes. Renal anatomy, size of hydronephrosis and presence of crossing vessels was evaluated with contrasted CT imaging. Pre-operative ureteral stenting or nephrostomy tube placement was not routinely performed unless for specific clinical reasons such as pain control.

All procedures were performed by 2 experienced laparoscopic (RSF, SBB) surgeons using Intuitive Surgical DaVinci S/Si system ${ }^{\circledR}$. A standard 3-arm technique was used with an additional assistant port. All procedures were performed transperitoneally. Dismembered pyeloplasty was performed in all cases with transposition of crossing vessels when present. Ureteral stent, typically positioned antegrade via the assistant port, was placed and confirmed in correct location with post-operative plain abdominal radiograph. Continuous bladder drainage via Foley catheter was maintained for 24-48 hours. Post-operative pain was managed with a combination of intravenous Ketorolac, narcotics and transitioned to oral med- ications once diet was advanced. Surgical drains, when placed, were removed prior to discharge unless high outputs were observed and/or fluid creatitine levels were greater than serum. Ureteral stents were removed after 3 weeks. Follow-up diuretic renal imaging was typically performed at 8 weeks.

\section{RESULTS}

55 adult patients underwent RAP (26 left/29 right) for UPJO including 9 secondary procedures from 2007 to 2009. Table-1 displays the cohort demographics. Average follow up was 16 months (1-36). Mean age was 41 years (18-71) with an average BMI of 27 (17-42); 32 were female. Most cases were diagnosed with preoperative diuretic renal scan (40 patients, 72\%) with obstructed side demonstrating mean function of $41 \%$ and $t 1 / 2$ of 70 minutes (Table-2). Mean operative time was 194 minutes with average blood loss less than $100 \mathrm{~mL}$. Mean hospital stay was 1.7 days with an average narcotic equivalent dose of $15 \mathrm{mg}$. On average, RAP for secondary UPJO took longer with more blood loss and had a lower success

Table 1 - Patient Characteristics.

\begin{tabular}{lc}
\hline Total renal units (side) & 55 (26 left, 29 right) \\
\hline Age, mean (range) & 41 years (18-79) \\
Male/Female & $23 / 32$ \\
Follow-up, mean (range) & 16 months (1-32) \\
BMI, mean (range) & $27(17-42)$ \\
Primary UPJO & 46 \\
Recurrent (secondary) UPJO & 9
\end{tabular}

rate (Table-3). Failure was defined as the need of another procedure due to persistent pain and/or obstruction on follow-up diuretic renal imaging. One patient (2\%) with primary UPJO failed and 2 patients (22\%) with secondary UPJO failed. One operative complication occurred secondary to trocar injury of the liver, requiring conversion to 
Table 2 - Perioperative Statistics.

\begin{tabular}{lc}
\hline Preoperative diuretic renal imaging & Mean (range) \\
\hline T 1⁄2, minutes & $70(20-376)$ \\
Function, \% & $41(14-50)$ \\
Operative time, minutes & $194(112-433)$ \\
Estimated blood loss, milliliters & $95(25-800)$ \\
Hospital stay, days & $1.7(1-3)$ \\
Narcotic use, morphine equivalents & $15(8-40)$ \\
\hline
\end{tabular}

open exploration for repair of the liver laceration. UPJO repair was completed prior to discovery of liver injury and subsequent exploration.

\section{DISCUSSION}

Treatment of UPJO remains an evolving process with the advancement of surgical technology. The comparative gold standard for successful treatment is open pyeloplasty, first performed in 1891 by Kuster (10). The demands of minimizing morbidity, faster convalescence, and shorter hospital stay have led to adoption and development of other procedures. In the 1980's, antegrade and then retrograde endopyelotomy was introduced along with the development of flexible ureteroscopy. Because these treatment options were less invasive and less morbid compared to open pyeloplasty, endoscopic procedures soon became the primary treatment of UPJO with open pyeloplasty being reserved for failed primary management. With the advent of urologic laparoscopy in the early 1990's, surgical correction of UPJO again changed when the first laparoscopic pyeloplasty was reported in 1993 (7). Further advancement was made with the incorporation of the robotic platform in 2000 (11).

RAP has outcomes similar to laparoscopic or open pyeloplasty for primary UPJO (12-15, Table-4). The long term results of Anderson-Hynes open pyeloplasty are greater that 95\% over about 10 years follow-up $(2,12)$ which is comparable to the long term results for laparoscopic pyeloplasty. In the largest laparoscopic pyeloplasty series of 147 patients published, the success rate was 95\% with average 24-month follow-up (13). While no side-by-side comparison between robotic pyeloplasty to open pyeloplasty has been made, multiple studies evaluating robotic and laparoscopic pyeloplasty are available (Table-4). A meta-analysis of 8 studies that compared laparoscopic to robotic pyeloplasty revealed a significantly shorter hospital stay in RAP by $1 / 2$ day, with no significant difference in operative time, rates of complications, re-admission rates, or success rates (14). In a single surgeon study from India that compared 30 RAP cases to 30 laparoscopic pyeloplasty cases, differences in operative time, blood loss and hospital stay were observed in favor of RAP. The success rates however were comparable (100\% laparoscopic pyeloplasty, 96.7\% in RAP) (15). Overall, robotic pyeloplasty shows a similar success rate compared to open and laparoscopic pyeloplasty while it may provide advantage in length of hospitalization and ease of surgery.

Table-5 lists the largest endopyelotomy series reported in the literature. A retrospective

Table 3 - Primary vs. Secondary UPJO.

\begin{tabular}{lcc}
\hline & Primary Mean (range) & Secondary Mean (range) \\
\hline T 1/2, minutes & $72(10-376)$ & $67(12-88)$ \\
Function, \% of total & $41(16-50)$ & $38(14-48)$ \\
Operative time, minutes & $192(112-270)$ & $205(144-433)$ \\
Estimated blood loss, $\mathrm{mL}$ & $90(25-200)$ & $125(25-800)$ \\
Failures & $1(2 \%)$ & $2(22 \%)$ \\
\hline
\end{tabular}


Table 4 - Laparoscopic/Robotic series.

\begin{tabular}{lcccccc}
\hline Study & \# patients & Lap/RAP & OR time & Hospital stay & Success & Complication \\
\hline Inagaki et al. (13) & 147 & Lap & 246 & 3.1 & $95 \%$ & $8.8 \%$ \\
Romero et al. (29) & 170 & Lap & 175.9 & 2.7 & $94.1 \%$ & $7.7 \%$ \\
Moon et al. (30) & 170 & Lap & 140 & 2.7 & $96.1 \%$ & $7.1 \%$ \\
Rassweiler et al. (18) & 143 & Lap & 125 & 5 & $94.4 \%$ & $6.3 \%$ \\
Symons et al. (31) & 118 & Lap & 205.4 & 4.7 & $94.5 \%$ & $11.9 \%$ \\
Schwenter et al. (22) & 92 & RAP & 108.3 & 4.6 & $96.7 \%$ & $3 \%$ \\
Mufarrij et al. (21) & 140 & RAP & 217 & 2.1 & $95.7 \%$ & $11 \%$ \\
Current study & 55 & RAP & 194 & 1.7 & $95 \%$ & $2.5 \%$ \\
\hline
\end{tabular}

Table 5 - Endopyelotomy series.

\begin{tabular}{lcccc}
\hline Study & \# patients & Success & $3 / 5 / 10$ year & Complication \\
\hline Knudsen et al. (32) & 80 & $67 \%$ & --- & --- \\
Ost et al. (19) & 50 & $84 \%$ & --- & -- \\
Dimarco et al. (17) & 225 & $61 \%$ & $63 / 55 / 41$ & $11.1 \%$ \\
Szydelko et al. (33) & 74 & $55.4 \%$ & --- & $22.5 \%$ \\
Rassweiler et al. (18) & 113 & $77.6 \%$ & --- & $5.3 \%$ \\
\hline
\end{tabular}

review by Yanke et al. (16) evaluating RAP, retrograde endopyelotomy and laparoscopic pyeloplasty with a mean follow-up of 20 months showed a success rate of $60.2 \%$ of the retrograde endopyelotomy group, $88.2 \%$ for laparoscopic pyeloplasty, and 100\% for RAP. Recurrence free survival for endopyelotomy was 50\% at 7 years compared with 76\% for laparoscopic pyeloplasty. Follow-up for RAP is currently in the beginning, however, it is assumed that RAP will likely mimic or may be better than the success rate of laparoscopic pyeloplasty over long-term. A retrospective review from Mayo Clinic (17) comparing antegrade endopyelotomy and pyeloplasty also showed similar findings. Endopyelotomy was found to be significantly inferior to pyeloplasty after 3,5 , and 10 years. The presence of extrinsic obstruction such as a crossing vessel or high grade hydronephrosis does not affect the outcome of operative pyeloplasty performed laparoscopic or with robot assistance (18). However, endopyelotomy success rates decreases significantly in the presence of these variables $(18,19)$. Therefore, while pyeloplasty may be universally applied, endopyelotomy can only be safely and efficaciously used in very limited scenarios and even then the overall success rates are not durable.

The primary purpose of this study is to report outcomes of RAP and endorse its role for treatment of primary UPJO. Operative time, blood loss and complication rates are similar to larger series in the literature (20). As for patient outcomes, 
while our overall success rate for primary UPJO are representative of what is reported in literature, our success rate for secondary UPJO is not. The overall success rate for our cohort is 95\%; 98\% for primary and 78\% for secondary UPJO. Most of the RAP series indicate an overall success rate between $89-100 \%$ (20). Muffarrij et al. reported an overall success rate of $95.7 \%(96.6 \%$ in primary, and $91.3 \%$ in the secondary) (21). Similar results were observed in the series by Schwenter (22). Although many studies do indicate the high overall success rates, not many studies report the success rate for RAP in secondary UPJO, and none analyze these systematically. However, those that report them do indicate a trend towards a decrease in success rates in the secondary UPJO. Our low success rate in secondary UPJO could also be due to low sample size.

Endopyelotomy is an inferior treatment for the vast majority of primary UPJO due to lower success rates and consequently will compromise the success of subsequent treatments. Endoscopic management can be useful as a secondary procedure following pyeloplasty as multiple retrospective studies have demonstrated some success. Hoenig et al. demonstrated that endopyelotomy after failed open pyeloplasty was successful in 71\% of cases. However, following primary endopyelotomy, endoscopic salvage is unlikely to relieve obstruction with success rate of $37.5 \%$ (23). Open repair for secondary obstruction demonstrates greater success with rates reported as high as 95\% (24). As for laparoscopic pyeloplasty for secondary UPJ obstruction after failed endopyelotomy, Sundaram reported an overall success rate of 83\% with higher complication rate and longer operative time (25). This is similar to our outcomes for secondary repairs. Overall, laparoscopic pyeloplasty/RAP for secondary UPJO after failed endopyelotomy shows a poor overall success rate, increased complication rate, and increased operating time.

RAP is minimally invasive with a decreased length of hospitalization and faster convalescence as compared to open pyeloplasty. While laparoscopic pyeloplasty is an excellent alternative to open surgery, the drawback is a steep learning curve, and the difficultly with intracor- poreal suturing (26). This limitation precludes its widespread use. In a contemporary survey study looking at current practice patterns of primary UPJO, 78\% of urologists in community practice stated they prefer an open approach while 67\% of academic urologists stated that they prefer a laparoscopic approach (27). RAP has a potentially shorter learning curve (28) and may enable laparoscopic-naive urologist to perform the procedure easily, bridging the gap between academic and community urologists. Therefore, we endorse RAP as the procedure of choice for primary UJPO reserving endopyelotomy for secondary procedures.

\section{CONCLUSIONS}

RAP is a good option for the treatment of patients with primary UPJO. Reported series have established that endopyelotomy has an inferior success rate for the treatment of primary UPJO which compromises the success of subsequent treatment as demonstrated by our higher failure rate with secondary UPJO repair.

\section{ABBREVIATIONS}

RAP: Robot-assisted pyeloplasty

UPJO: Ureteropelvic junction obstruction

\section{ACKNOWLEDGEMENTS} collection.

Cathy Chen, RN for assistance with data

This project was funded in part by a grant from Midwest Stone Institute

\section{CONFLICT OF INTEREST}

Matthew Thom - None

Mohammed Haseebuddin - None

Timur M Roytman - None

Brian M Benway - Consultant, Viking systems

Surgical

Sam B Bhayani - Consultant, Intuitive

Robert S Figenshau - None 


\section{REFERENCES}

1. Arun N, Kekre NS, Nath V, Gopalakrishnan G: Is open pyeloplasty still justified? Br J Urol. 1997; 80: 379-81.

2. O'Reilly PH, Brooman PJ, Mak S, Jones M, Pickup C, Atkinson $\mathrm{C}$, et al.: The long-term results of Anderson-Hynes pyeloplasty. BJU Int. 2001; 87: 287-9.

3. Brooks JD, Kavoussi LR, Preminger GM, Schuessler WW, Moore RG: Comparison of open and endourologic approaches to the obstructed ureteropelvic junction. Urology. 1995; 46: 791-5.

4. Gill HS, Liao JC: Pelvi-ureteric junction obstruction treated with Acucise retrograde endopyelotomy. Br J Urol. 1998; 82: 8-11.

5. Danuser H, Hochreiter WW, Ackermann DK, Studer UE: Influence of stent size on the success of antegrade endopyelotomy for primary ureteropelvic junction obstruction: results of 2 consecutive series. J Urol. 2001; 166: 902-9.

6. Albani JM, Yost AJ, Streem SB: Ureteropelvic junction obstruction: determining durability of endourological intervention. J Urol. 2004; 171: 579-82.

7. Schuessler WW, Grune MT, Tecuanhuey LV, Preminger GM: Laparoscopic dismembered pyeloplasty. J Urol. 1993; 150: 1795-9.

8. Zhang X, Li HZ, Ma X, Zheng T, Lang B, Zhang J, et al.: Retrospective comparison of retroperitoneal laparoscopic versus open dismembered pyeloplasty for ureteropelvic junction obstruction. J Urol. 2006; 176: 1077-80.

9. Marcovich R, Jacobson Al, Aldana JP, Lee BR, Smith AD: Practice trends in contemporary management of adult ureteropelvic junction obstruction. Urology. 2003; 62: 22-5; discussion 25-6.

10. Poulakis V, Witzsch U, Schultheiss D, Rathert P, Becht E: History of ureteropelvic junction obstruction repair (pyeloplasty). From Trendelenburg (1886) to the present. Urologe A. 2004; 43: 1544-59.

11. Gettman MT, Neururer R, Bartsch G, Peschel R: AndersonHynes dismembered pyeloplasty performed using the da Vinci robotic system. Urology. 2002; 60: 509-13.

12. Gögüs $C$, Karamürsel $T$, Tokatli $Z$, Yaman 0 , Ozdiler $E$, Gögüs 0: Long-term results of Anderson-Hynes pyeloplasty in 180 adults in the era of endourologic procedures. Urol Int. 2004; 73: 11-4.

13. Inagaki T, Rha KH, Ong AM, Kavoussi LR, Jarrett TW: Laparoscopic pyeloplasty: current status. BJU Int. 2005; 95(Suppl 2): 102-5.

14. Braga LH, Pace K, DeMaria J, Lorenzo AJ: Systematic review and meta-analysis of robotic-assisted versus conventional laparoscopic pyeloplasty for patients with ureteropelvic junction obstruction: effect on operative time, length of hospital stay, postoperative complications, and success rate. Eur Urol. 2009; 56: 848-57.

15. Hemal AK, Mukherjee S, Singh K: Laparoscopic pyeloplasty versus robotic pyeloplasty for ureteropelvic junction obstruction: a series of 60 cases performed by a single surgeon. Can J Urol. 2010; 17: 5012-6.

16. 1Yanke BV, Lallas CD, Pagnani C, McGinnis DE, Bagley DH: The minimally invasive treatment of ureteropelvic junction obstruction: a review of our experience during the last decade. J Urol. 2008; 180: 1397-402.

17. Dimarco DS, Gettman MT, McGee SM, Chow GK, Leroy AJ, Slezak J, et al.: Long-term success of antegrade endopyelotomy compared with pyeloplasty at a single institution. J Endourol. 2006; 20: 707-12.

18. Rassweiler JJ, Subotic S, Feist-Schwenk M, Sugiono M, Schulze M, Teber D, et al.: Minimally invasive treatment of ureteropelvic junction obstruction: long-term experience with an algorithm for laser endopyelotomy and laparoscopic retroperitoneal pyeloplasty. J Urol. 2007; 177: 1000-5.

19. Ost MC, Kaye JD, Guttman MJ, Lee BR, Smith AD: Laparoscopic pyeloplasty versus antegrade endopyelotomy: comparison in 100 patients and a new algorithm for the minimally invasive treatment of ureteropelvic junction obstruction. Urology. 2005; 66(5 Suppl): 47-51.

20. Atalla MA, Dovey Z, Kavoussi LR: Laparoscopic versus robotic pyeloplasty: man versus machine. Expert Rev Med Devices. 2010; 7: 27-34.

21. Mufarrij PW, Woods $M$, Shah OD, Palese MA, Berger AD, Thomas $\mathrm{R}$, et al.: Robotic dismembered pyeloplasty: a 6-year, multi-institutional experience. J Urol. 2008; 180: 1391-6.

22. Schwentner $C$, Pelzer A, Neururer $R$, Springer B, Horninger W, Bartsch G, et al.: Robotic Anderson-Hynes pyeloplasty: 5-year experience of one centre. BJU Int. 2007; 100: 880-5.

23. Hoenig DM, Shalhav AL, Elbahnasy AM, McDougall EM, Smith D, Clayman RV: Impact of etiology of secondary ureteropelvic junction obstruction on outcome of endopyelotomy. J Endourol. 1998; 12: 131-3.

24. Gupta M, Tuncay OL, Smith AD: Open surgical exploration after failed endopyelotomy: a 12-year perspective. J Urol. 1997; 157: 1613-8; discussion 1618-9.

25. Sundaram CP, Grubb RL 3rd, Rehman J, Yan Y, Chen C, Landman J, et al.: Laparoscopic pyeloplasty for secondary ureteropelvic junction obstruction. J Urol. 2003; 169: 2037-40.

26. Singh 0, Gupta SS, Arvind NK: Laparoscopic pyeloplasty: an analysis of first 100 cases and important lessons learned. Int Urol Nephrol. 2011; 43: 85-90.

27. Tan BJ, Rastinehad AR, Marcovich R, Smith AD, Lee BR: Trends in ureteropelvic junction obstruction management among urologists in the United States. Urology. 2005; 65: 260-4. 
28. Passerotti CC, Passerotti AM, Dall'Oglio MF, Leite KR, Nunes RL, Srougi M, et al.: Comparing the quality of the suture anastomosis and the learning curves associated with performing open, freehand, and robotic-assisted laparoscopic pyeloplasty in a swine animal model. J Am Coll Surg. 2009; 208: 576-86.

29. Romero FR, Wagner AA, Trapp C, Permpongkosol S, Muntener M, Link RE, Kavoussi LR. Transmesenteric laparoscopic pyeloplasty. J Urol. 2006; 176: 2526-9.

30. Moon DA, El-Shazly MA, Chang CM, Gianduzzo TR, Eden CG. Laparoscopic pyeloplasty: evolution of a new gold standard. Urology. 2006; 67: 932-6.

31. Symons SJ, Bhirud PS, Jain V, Shetty AS, Desai MR. Laparoscopic pyeloplasty: our new gold standard. J Endourol. 2009; 23: 463-7.

32. Knudsen BE, Cook AJ, Watterson JD, Beiko DT, Nott L, Razvi $H$, Denstedt JD. Percutaneous antegrade endopyelotomy: long-term results from one institution. Urology. 2004; 63: 230-4.
33. Szydelko T, Kopec R, Kasprzak J, Apoznanski W, Kolodziej A, Zdrojowy R, Lorenz J. Antegrade endopyelotomy versus laparoscopic pyeloplasty for primary ureteropelvic junction obstruction. J Laparoendosc Adv Surg Tech A. 2009; 19: 45-51.

Correspondence address: Dr. Sherb Figenshau

Division of Urologic Surgery Taylor Family - Ralph V. Clayman, M.D. Division of Urology

Washington University School of Medicine Telephone: + 1314 454-2235 E-mail: figenshaur@wustl.edu 